\title{
Negotiating with Iran
}

John W. Limbert

Washington, DC: United States Institute for Peace Press, 2009. 200 pages.

In his preface to this book, Mark Bowden states that John Limbert is "the best American friend Iran had" (p. ix) and that the United States is "not a nineteenth-century-style imperial power bent on colonizing smaller nations." Thus, Iranian suspicions of it as well as their suspecting (re)actions 
were "inexplicable." This was particularly so as in the case when the United States became one of the "primary victims of Iran's assault on international civility" (pp. x-xi). With this auspicious introduction, Bowden inaugurates Limbert's study on how to negotiate with Iran.

Limbert opens with recalling the events of 1979 that led to him, as well as his "diplomatic" colleagues, becoming hostages in the American embassy compound. In the introduction, he cites errors committed by American officials back home who did not seem to have a clear picture of on-the-ground realities in Iran and thus made "bad policy decisions" (p. 5). He also blamed himself for an "error of judgment": being the only Persian-speaking American, he went out to meet the students and try to negotiate some sense into them. Whereas both American "errors" were due to a lack of understanding and perhaps "foolish" altruism, the latter one was inspired by Limbert's experience in dealing with Iranian high school and university students in a nonconfrontational way when they tried to "cheat" (p. 3). Thus Iran's best friend makes a subtle contrast between American and Iranian (being Oriental) mistakes, all the while asserting the need to avoid stereotypes and labeling (p. 6). American "errors" are caused by misunderstandings and naiveté, yet still with the best of intentions, whereas those of the Iranians are due to a natural inclination toward deviousness.

At any rate, Limbert offers his book both as a contribution to future negotiating efforts and his "Iranian" experience prospective American negotiators. He emphasizes the need to remember that the Iranians' strong sense of historical grandeur, grievances, and humiliations (p. 7) are historical and cultural constants (p. 12). The author therefore adopts a comparative methodology that incorporates Iran's negotiating experiences with the West: the Azerbaijan crisis of 1945-47, the oil nationalization crisis of 1951-53, the hostage crisis of 1979-81, and the Lebanon hostage crisis of 1985-91. Each crisis is examined separately (chapters 2-5); chapter 6 identifies fourteen lessonslearned steps to be followed, and chapter 7 suggests how mutual misperceptions can be overcome.

The Azerbaijan crisis reflected Iran's weakness when, during WWII, Britain, the USSR, and the United States occupied it in 1941 as part of their joint efforts against Germany. The occupation also ended Reza Shah's centralized rule, due to his pro-German sympathies, and enabled the eruption of centrifugal forces that threatened the country's unity. In the absence of state authority, aggrieved local Azerbaijani movements (including the communist Tudeh party) called for autonomy and separation and actually received Soviet assistance. This was considered an infringement upon the 1941 tripartite agreement to withdraw from Iran once the war ended. 
In late 1945, Tehran faced a serious situation: the threatened loss of some of its richest and most important regions (p. 39). At the same time, Moscow was imposing concessionary demands that, if accepted, would have dealt a serious blow to Iranian sovereignty. Under these grim conditions, Prime Minister Ahmad Qavam (1946) had to negotiate oil concessions with the Soviets in an effort to gain their trust and their willingness to withdraw. Tehran subsequently crushed the separatist forces in Azerbaijan, after which its parliament rejected the oil concession in 1947 and Qavam resigned. The lessons learned here are that the Iranians did not attempt to present their position in legal terms, but rather in terms of trust and friendship; they improvised and, despite factionalism, were united on fundamental questions of national unity and sought to make the most of a weak hand.

Chapter 3 deals with the oil nationalization crisis, which to a large extent precipitated the post-revolution hostage crisis of the late 1970s. The crisis began when the democratically elected Prime Minister Muhammad Mosaddegh sought to nationalize the Iranian oil industry, controlled at the time by the Anglo-Persian Oil Company (APOC). This led to his overthrow in 1953 via a coup organized by the British and American intelligence services (p. 75) - an event that remains a festering wound in the Iranian psyche (pp. 85-86). The lessons learned here are that mutual misperceptions were largely a product of inequalities and historical grievances on part of the weaker side: Iran. Limbert also observed that Iran was negotiating in terms of abstract notions of justice apart of interests, whereas the British and Americans could not separate the person of Mosaddegh from the problem at hand. He suggested that they should have been able to do so (pp. 82-85).

This crisis and its aftermath spilled over into another one: the Carter administration's decision to admit the cancer-stricken shah on "humanitarian" grounds. Suspecting that Washington was preparing something akin to the 1953 coup, a group of students invaded the embassy compound and precipitated the hostage crisis. According to Limbert, this gave the radicals the upper hand in controlling subsequent events. He viewed this a decision as one of a series of "mistakes" and "misjudgments" (p. 88). American officials should have expected the unusual while avoiding easy assumptions about what the Iranians may or may not be willing to do. This would have been possible had they consulted with people who knew Iran well, like himself, and had been aware of the grievances and ghosts of the past. After this came another crisis: American citizens were taken hostage by perceived Iranian allies in Lebanon. This led to a long process of acrimonious exchanges as the hostages became pawns in arms-for-hostages dealings (chapter 5). 
After these case analyses, the author uses chapter 6 to present his "fourteen steps to success" in negotiating with Iran: avoid too much legalism while establishing objective criteria; be aware of Iran's historical perceptions and grievances; be careful to choose credible intermediaries; talk to the people who can make and enforce decisions; be aware of the Islamic regime's priority of survival; let Iranians define their own national interest; expect actions that may appear (to American counterparts) as self-destructive; give Iranians credit for intelligence; expect vague and uncertain claims as well as grandstanding and flamboyant gestures; remember that power is respected and weakness despised; understand that justice, even in the abstract, is very important to Iranians; remember that conspiracy theories thrive and in many cases are, in fact, true; and expect hands to be overplayed. In chapter 7, Limbert touches upon each side's negative perceptions of the other. He suggests that such "myths" and "stereotypes" can be overcome by approaching negotiations with Iran in a "paradoxical" way that would harbor both low and high expectations without being governed or constrained by preconceptions and/or prejudices.

Whether his guiding map can help bring about some form of American-Iranian negotiations or reconciliation is, of course, an empirical matter. The real question is whether a leopard can change its spots. Suffice it to say that much of how Washington has dealt with and done to Iran closely resembles what it is now doing in Egypt. Much of what the author stresses as perceptions and misunderstandings may perhaps be far more than that. It may, in fact, already be too late to follow his suggested guiding points in the case of Iran. Would he suggest the same before it is too late to do so in Egypt? 